
\title{
28 Research Square \\ Is COVID-19 a risk factor of DVT in orthopaedic trauma surgery? A prospective study
}

\section{Anıl Agar ( $\nabla$ dr.anilagar@hotmail.com )}

Istanbul Kanuni Sultan Suleyman Egitim ve Arastirma Hastanesi https://orcid.org/0000-0003-23447801

\section{Orhan Gunes}

Istanbul Kanuni Sultan Suleyman Egitim ve Arastirma Hastanesi

Adem Sahin

Istanbul Kanuni Sultan Suleyman Egitim ve Arastirma Hastanesi

\section{Bulent Kılıc}

Istanbul Kanuni Sultan Suleyman Egitim ve Arastirma Hastanesi

\section{Sumeyra Dogan}

Istanbul Kanuni Sultan Suleyman Egitim ve Arastirma Hastanesi

\section{Ali Kocatas}

Istanbul Kanuni Sultan Suleyman Egitim ve Arastirma Hastanesi

\section{Deniz Gulabi}

Istanbul Kanuni Sultan Suleyman Egitim ve Arastirma Hastanesi

\section{Cemil Erturk}

Istanbul Kanuni Sultan Suleyman Egitim ve Arastirma Hastanesi

\section{Research article}

Keywords: COVID19, lower extremity, fracture, d-dimer, DVT, doppler USG

Posted Date: August 12th, 2020

DOI: https://doi.org/10.21203/rs.3.rs-47416/v2

License: (c) (1) This work is licensed under a Creative Commons Attribution 4.0 International License.

Read Full License 


\section{Abstract}

Objective: The aim of this prospective study was to evaluate the radiological and laboratory parameters of patients diagnosed with COVID-19 who underwent surgery for a lower extremity fracture in our COVID19 care units in terms of DVT.

Patients and Methods: Patients who were operated on due to lower extremity fracture between 10 March and 1 May and diagnosed with COVID-19 were evaluated prospectively. Patients' age, gender, affected side, fracture location, fracture type, COVID-19 radiological or clinical symptoms and Doppler USG and biochemical markers screening for DVT were evaluated.

Results: Thirty patients, ages 39-88, were included in the study. Preoperative D-dimer value of the patients was mean $5.9 \mathrm{mg} / \mathrm{L}$. In all the patients, the D-dimer level was above the normal range. The mean troponin value was $0.025 \mathrm{ng} / \mathrm{mL}$ preoperatively. The troponin value was found to be normal in 8 patients and above the normal value in 22 patients. On physical examination, DVT findings were present in 1 patient and DVT was detected in 2 patients on doppler ultrasound.

Conclusion: It can be recommended that extra attention should be given to vascular complications in COVID-19 positive trauma patients, as both the effect of trauma itself increases hypercoagulability and COVID-19 disease seems to have the potential to increase hypercoagulability.

\section{Introduction}

Deep vein thrombosis (DVT) is a blood clot that forms in a deep vein in the human body. Blood clots appear when the blood gets darker or accumulates. Although DVT can occur in any part of the body, in any area where there are branches of the venous circulation, most deep vein blood clots develop in the lower leg or thigh. DVT is the third most common cardiovascular disease (CVD) with an annual incidence of approximately 1-2 per 1000 people in the general population(1). The most serious complication is pulmonary embolism (PE), which is associated with a significant number of deaths(2). Patients with suspected DVT are common in hospital emergency rooms and there are common symptoms such as tenderness or swelling in the leg, although relatively few suspected patients also have possible DVT(3). About two-thirds of episodes appear as DVT and one-third as PE without or with DVT $(4,5)$. In the current trend for surgery without prophylaxis towards VTE, the occurrence of DVT has been said to be as high as $30 \%$, with an associated mortality risk of $1 \%(6)$. Venous thromboembolic events are also not unusual and constitute life threatening complications after a worrying injury(7-9). Coagulopathy has been reported to be present on admission in $25 \%$ of trauma patients, and has been related to a 5 -fold boom in mortality(10). In an autopsy study on 125 cadavers, DVT was reported at a rate of $65 \%$ and pulmonary embolizm at $16 \%(11)$. The occurrence of DVT varies from $5 \%$ to $63 \%$ in trauma patients, depending on the patient risk factors, modality of prophylaxis, and strategies of detection(12,13).

Coronavirus disease (COVID-19) is a serious acute respiratory syndrome caused by the new strain of coronavirus, which was declared a pandemic by the World Health Organization on March 11, 2020, and it 
can also lead to systemic coagulation activation. Initial research from China showed that $46-63 \%$ of patients had increased levels of D-dimers $(\geq 0.5 \mathrm{mg} / \mathrm{L})$, and there can be other signs and symptoms such as mild coagulation activation, thrombocytopenia and moderately prolonged prothrombin time $(14,15)$. In addition, patients who developed a serious disease course, including admission to the intensive care unit (ICU) and death, seem to have developed more pronounced coagulation activation. For example, patients who died from COVID-19 had higher D-dimers than survivors on admission, and during hospital stay(16). In another study, patients with $\geq 1.0-\mu \mathrm{g} / \mathrm{L}$ D-dimer had an 18-fold increased risk of death(15). In Turkey, antithrombotic therapy was initiated after hospitalization and discharge to patients in the high-risk group with predisposing factors.

The aim of this prospective study was to evaluate the doppler ultrasonographic and laboratory parameters of patients diagnosed with COVID-19 who underwent surgery for a lower extremity fracture in our COVID-19 care units in terms of DVT.

\section{Patients And Methods}

This prospective study was approved by the Local Ethics Committee of Istanbul provincial health directorate. On 10 March 2020 the Republic of Turkey Ministry of Health designated all public and private hospitals and university hospitals as pandemic hospitals. All trauma patients hospitalized after this date were routinely screened for COVID-19. This prospective study included patients who were operated on for lower limb trauma between 10 March and 1 May, and had been screened for COVID-19. The study inclusion criteria were COVID-19 positivity, a lower extremity fracture, and no additional disease that may cause hypercoagulopathy. Patients were excluded from the study if they had not been diagnosed with COVID-19, did not have a lower limb fracture, did not have previous history of vascular disease, had any additional systemic disease that may cause DVT, had family history and nutritional deficiencies predisposing for DVT or had lower extremity amputation.

All patient data were collected by an orthopaedic resident blinded to the study. The data included age, gender, affected side, fracture location, fracture type, COVID-19 radiological or clinical symptoms and Doppler USG and biochemical markers screening for DVT.

During the pandemic period, COVID-19 screening was performed routinely with low-dose lung CT for all trauma patients who were first examined in the hospital emergency department and were then admitted to the hospital (figure 1). In addition, for patients with a history of fever, dyspnea, or contact with a COVID19 positive person, nose and throat swabs were taken and PCR was examined for COVID-19. When a suspected or definitive COVID-19 diagnosis was made, trauma patients were taken to the in-patient isolation wards for COVID-19 in our hospital. Low molecular weight heparin was routinely started for all hospitalized patients. Enoxoparin sodium $0.4 \mathrm{ml} / 4000$ anti-Xa was started subcutaneously from the moment of hospitalization. The anticoagulant therapy was discontinued 12 hours before surgery and resumed 24 hours after surgery. When the patients were discharged, enoxoparin sodium $0.4 \mathrm{~mL}$ was continued subcutanously for 30 days postoperatively. Mechanical thrombo-prophylaxis (pressure pump, 
20 min twice a day) was also used. D-dimer and troponin levels were measured on or within 24 hours of admission of the patients for DVT screening before the surgery and DVT screening was performed in the physical examination. Physical examination of all patients was performed by the general surgeon (A.K.) who has experience in vascular surgery. The patients, whose preparations for surgical intervention were completed, underwent orthopedic surgery in the operating rooms of our hospital, which were specifically isolated for COVID-19 positive patients $(17,18)$. Postoperative follow-up of the patients was continued in the isolation wards. Bilateral lower extremity Doppler USG was performed on postoperative day 1 for DVT screening. All venous ultrasound in this patient group were performed by the same radiologist with 10 years of experience after taking all precautions for COVID-19 (figure 2). One ultrasonography scanner (Aplio 500, Toshiba Medical Systems Corp., Otawara, Japan) with a 4.8 to $11 \mathrm{MHz}$ high-frequency lineararray transducer was used in all cases. As the routine venous ultrasound protocol, deep veins from the groin to the ankle including the external iliac, common femoral, superficial femoral, popliteal, tibiofibular trunk, posterior tibial and peroneal veins were assessed both transverse and sagittal planes in the supine and/or prone position. Detecting intraluminal thrombus material, absence of compressibility, or lack of blood flow in a venous segment were accepted as the diagnostic criteria of deep venous thrombus.

Postoperatively, routine orthopedic physical therapy and follow-up procedures were applied, and the treatment of patients was continued for COVID-19. The patients were discharged from the hospital after the COVID-19 treatment was completed on the decision of the infectious diseases specialist.

\section{Results}

During the stated period of the pandemic, 41 patients were hospitalized and operated on for lower extremity fractures and of these patients, 11 were excluded from the study because they did not meet the inclusion criteria. Therefore, evaluation was made of 30 patients aged $39-88$ years between the dates of 10 March-1 May. The patients comprised 16 females and 14 males with a mean age of 69.3 years, average height of $166.4 \mathrm{~cm}$, and average weight of $77.6 \mathrm{~kg}$. Fourteen patients had fractures in the right and sixteen in the left lower extremity. Intertrochanteric femur fracture was determined in 12 patients, femoral neck fracture in 5 patients, femur diaphyseal fracture in 4 patients, subtrochanteric femur fracture in 2 patient, femur distal fracture in 2 patients, tibial plateau fracture in 2 patient, periprosthetic femur fracture in 1 patient, bimalleolar fracture in 1 patient, and patella fracture in 1 patient.

The preoperative D-dimer value of the patients was mean $5.9 \mathrm{mg} / \mathrm{L}$ (D-dimer normal range 0-0.55 mg / L) (range, $0.82 \mathrm{mg} / \mathrm{L}-21.1 \mathrm{mg} / \mathrm{L}$ ). In all the patients, the D-dimer level was above the normal range. Preoperative troponin values were examined as another parameter for DVT scanning; the lowest value was $0.01 \mathrm{ng} / \mathrm{mL}$, the highest value was $0.1 \mathrm{ng} / \mathrm{mL}$ and the average value was $0.025 \mathrm{ng} / \mathrm{mL}$ (troponin normal range $0-0.014 \mathrm{ng} / \mathrm{mL}$ )(table1). The troponin value was found to be normal in 8 patients and above the normal value in 22 patients. In the physical examination of the patients, swelling of the limb was observed in all patients, while the Homans test performed for the purpose of DVT scanning was observed to be positive in only 1 patients. The Homan test has sensitivity of $60-88 \%$ and specificity of $30-$ $72 \%$. 
On Doppler ultrasound performed on the postoperative first day, 2 patients had DVT. One of the patients with DVT detected had a periprosthetic femur fracture, while the other patient had a femur diaphyseal fracture. Thrombus of one patient was observed in the left and the other in the right popliteal vein (figure 3). In this patients the preoperative d-dimer levels were $2.54 \mathrm{mg} / \mathrm{L}$ and $4.11 \mathrm{mg} / \mathrm{L}$, and the preoperative troponin levels were $0.02 \mathrm{ng} / \mathrm{mL}$ and 0,017 ng / $\mathrm{mL}$. Antithrombotic treatment was started after the patients were diagnosed with DVT. No findings suggestive of DVT were detected on the Doppler ultrasound of any other patient (figure 4).

\section{Discussion}

The main findings of the present study were that D-dimer level and Troponin levels were detected higher than normal in COVID-19 positive trauma patients, although no significant vascular pathology could be detected in these COVID-19 positive trauma patients, as reported in the literature $(19,20)$.

Three important factors for thrombus formation within the vein, blood flow, blood component and blood vessels have been recognized as the Virchow triad(21). Major trauma can lead to collapse of one or all of the Virchow triad of hypercoagulation, endothelial injury, and venous stasis(22). Long-term bed rest, immobilization, or thrombosis caused by direct damage to blood vessels can cause intimal damage, leading to hypoperfusion and paralysis, and all these factors support venous stasis. Hak stated that the Virchow triad is present in the majority of trauma patients and this causes a high risk of thromboembolism(23). Reduced antithrombin III levels $(24,25)$ and suppression of fibrinolysis $(26,27)$ can cause hypercoagulation of the trauma patient. Okamura et al. reported that the levels of d-dimer and soluble fibrin monomer complex were higher than normal in patients with hip fractures(28). Many studies have shown that after trauma, thromboplastin (Tissue factor; TF) and thrombin formation markers are increased and natural anticoagulant levels such as antithrombin (AT), protein C (PC) and protein S (PS) are decreased(29-31). In addition to the consumption of coagulation factors, acidosis and hypothermia and dilution of intravenous fluids that occurs as a result of decreased activity are among the causes of traumatic coagulopathy(10). Inactivity is also a known cause of VTE. The absence of the pumping effect of muscle contractions leads to a decrease in blood flow and accumulation of blood in the calf intramuscular sinuses, resulting in DVT(32). Increased hematocrit, high fibrinogen and von Willebrand factor macromolecular complex levels increase blood viscosity, which may further affect blood flow(33). Reduced blood flow can lead to endothelial damage, local accumulation of activation products, clotting products and local reduction in inhibitor levels, which increase blood coagulability(34).

COVID-19 is a severe acute respiratory syndrome disease caused by coronavirus 2 (SARS-CoV-2), and can also make patients prone to thrombotic disease in both venous and arterial circulation due to excessive inflammation, platelet activation, and endothelial dysfunction(35). Some recent studies have reported that the incidence of arterial and venous thrombosis is higher in COVID-19 patients(18,36,37). In the present study $6.7 \%$ of the patients had DVT. In a retrospective study by Cui et al., $25 \%$ of 81 severe COVID19-positive patients followed up in intensive care were reported to have VTE(38). In a multicentre study of 184 patients with severe COVID-19 from the Netherlands, 28 (15.2\%) VTE cases were reported and the 
cumulative incidence of VTE was estimated to be $27 \%(39)$. Rodriguez et al. stated that 23 of 156 patients had DVT in their retrospective study and as in other series, the probability of developing DVT was high in patients with COVID-19 positivity and a high D-dimer level(19). The low incidence of DVT in the patients in the current series can be considered to be due to the initiation of antithrombotic medication and wearing antiembolic socks from the time of hospitalization, and in-bed exercise was also started immediately on hospitalization. Moreover, none of the patients in the current study had severe COVID-19 disease.In the present study, all the patients operated on for lower limb fractures were discharged with routine COVID-19 therapy, and none developed severe COVID-19 disease.

The D-dimer levels were found to be above the normal level in all the patients screened, but this was predictable due to both trauma and COVID-19 positivity. However, DVT was detected radiologically in only two of these patients and thrombolytic therapy was started. Cardiovascular surgery consultation was requested for the patient with DVT and $0.6 \mathrm{ml}$ of enoxoparin sodium was started twice a day with the recommendation of cardiovascular surgery and it was recommended to continue using antiembolic socks. Following the completion of the orthopedic treatment, the patient was followed up for the DVT treatment by the cardiovascular surgeon. The high D-dimer level in the other patients could have been secondary to trauma or due to COVID-19 disease alone.

The cardiac troponin level in the blood tends to increase in trauma patients without cardiac trauma, and also tends to increase in situations where the right ventricle of the heart is forced, such as in the occurrence of pulmonary embolism. In the current study, troponin levels were also investigated and levels above normal were determined in 22 patients.

There were several limitations to this study, primarily the low small sample size, the lack of long-term follow-up, and none of the patients followed up had severe COVID-19 disease. There is a clear need for further large series to be able to make comparisons with COVID-19 negative patients and similar traumas.

In conclusion, it can be recommended that extra attention should be given to vascular complications in COVID-19 positive trauma patients, as both the effect of trauma itself increases hypercoagulability and COVID-19 disease seems to have the potential to increase hypercoagulability.

\section{Declarations}

\section{Acknowledgements}

We thank Nihal Ozdemir for assistance in the statistical analysis of our data and preparation of table for this article.

\section{Funding}

None

\section{Author information}




\section{Affiliations}

1. Anil Agar, MD, Consultant Orthopaedic Surgeon. Saglik Bilimleri University, Kanuni Sultan Suleyman training and research hospital, Orthopaedic and Traumatology Department, Atakent mah, Istanbul cad. No:1, 34303, Kucukcekmece/ Istanbul,Turkey, dr.anilagar@hotmail.com Orcid: 0000-0003-23447801

2. Orhan Gunes, M.D. Consultant Orthopaedic Surgeon Assistant. Saglik Bilimleri University, Kanuni Sultan Suleyman training and research hospital, Orthopaedic and Traumatology Department, Atakent mah, Istanbul cad. No:1, 34303, Kucukcekmece/Istanbul, Turkey, gunesorhann@gmail.com Orcid: 0000-0001-6166-1118

3. Adem Sahin, M.D., Consultant Orthopaedic Surgeon. Saglik Bilimleri University, Kanuni Sultan Suleyman training and research hospital, Orthopaedic and Traumatology Department, Atakent mah, Istanbul cad. No:1, 34303, Kucukcekmece/ Istanbul,Turkey ademtito@yahoo.com. Orcid: 0000-00024020-9488

4. Bulent Kilic, M.D., Consultant Orthopaedic Surgeon. Saglik Bilimleri University, Kanuni Sultan Suleyman training and research hospital, Orthopaedic and Traumatology Department, Atakent mah, Istanbul cad. No:1, 34303, Kucukcekmece/ Istanbul,Turkey, drbulentk@hotmail.com Orcid: 00000001-8101-804X

5. Sumeyra Dogan, M.D., Consultant Radiologist. Saglik Bilimleri University, Kanuni Sultan Suleyman training and research hospital, Radiology Department, Atakent mah, Istanbul cad. No:1, 34303, Kucukcekmece/ Istanbul,Turkey, sdogan79@gmail.com Orcid:0000-0003-0954-2722

6. Ali Kocatas, MD, Assoc. Prof., Consultant General Surgeon. Saglik Bilimleri University, Kanuni Sultan Suleyman training and research hospital, Orthopaedic and Traumatology Department, Atakent mah, Istanbul cad. No:1, 34303, Kucukcekmece/ Istanbul,Turkey, drkocatas@yahoo.comOrcid: 0000-00032424-8900

7. Deniz Gulabi, MD, Assoc. Prof., Consultant Orthopaedic Surgeon. Saglik Bilimleri University, Kanuni Sultan Suleyman training and research hospital, Orthopaedic and Traumatology Department, Atakent mah, Istanbul cad. No:1, 34303, Kucukcekmece/Istanbul, Turkey, dgulabi@yahoo.com Orcid: 00000002-4131-7536

8. Cemil Erturk, MD, Prof., Consultant Orthopaedic Surgeon. Saglik Bilimleri University, Kanuni Sultan Suleyman training and research hospital, Orthopaedic and Traumatology Department, Atakent mah, Istanbul cad. No:1, 34303, Kucukcekmece/ Istanbul,Turkey, erturkc@yahoo.com Orcid: 0000-00029225-917X

\section{Contributions}

All authors have a substantial contribution in the study design, data interpretation and writing and reviewing the manuscript. The authors read and approved the final manuscript. 
Correspondence to Anil Agar.

\section{Ethics declarations}

Ethics approval and consent to participate

Ethics committee approval was obtained from the Istanbul University of Health Sciences Kanuni Sultan Suleyman Training and Research Hospital with the number 2020.07.113.

\section{Consent for publication}

Not applicable.

\section{Competing interests}

The authors declare no conflict of interest.

\section{Abbreviations}

DVT: Deep vein thrombosis

CVD: Cardiovascular disease

PE: Pulmonary embolism

COVID-19: Coronavirus disease

ICU: Intensive care unit

USG: Ultrasonography

CT: Computed tomography

PCR: Polymerase Chain Reaction

VTE: Venous thromboembolism

\section{References}

1. Silverstein, M. D., Heit, J. A., Mohr, D. N., Petterson, T. M., O'Fallon, W. M., \& Melton, L. J., 3rd (1998). Trends in the incidence of deep vein thrombosis and pulmonary embolism: a 25-year populationbased study. Archives of internal medicine, 158(6), 585-593

2. Anderson, F. A., Jr, Wheeler, H. B., Goldberg, R. J., Hosmer, D. W., Patwardhan, N. A., Jovanovic, B., Forcier, A., \& Dalen, J. E. (1991). A population-based perspective of the hospital incidence and case- 
fatality rates of deep vein thrombosis and pulmonary embolism. The Worcester DVT Study. Archives of internal medicine, 151(5), 933-938.

3. Hull, R., \& Hirsh, J. (1981). Advances and controversies in the diagnosis, prevention, and treatment of venous thromboembolism. Progress in hematology, 12, 73-123

4. Cushman M. (2007). Epidemiology and risk factors for venous thrombosis. Seminars in hematology, 44(2), 62-69

5. Knudson, M. M., Ikossi, D. G., Khaw, L., Morabito, D., \& Speetzen, L. S. (2004). Thromboembolism after trauma: an analysis of 1602 episodes from the American College of Surgeons National Trauma Data Bank. Annals of surgery, 240(3), 490-498.

6. Eppsteiner, R. W., Shin, J. J., Johnson, J., \& van Dam, R. M. (2010). Mechanical compression versus subcutaneous heparin therapy in postoperative and posttrauma patients: a systematic review and meta-analysis. World journal of surgery, 34(1), 10-19

7. Paffrath, T., Wafaisade, A., Lefering, R., Simanski, C., Bouillon, B., Spanholtz, T., Wutzler, S., Maegele, M., \& Trauma Registry of DGU (2010). Venous thromboembolism after severe trauma: incidence, risk factors and outcome. Injury, 41(1), 97-101.

8. Reiff, D. A., Haricharan, R. N., Bullington, N. M., Griffın, R. L., McGwin, G., Jr, \& Rue, L. W., 3rd (2009). Traumatic brain injury is associated with the development of deep vein thrombosis independent of pharmacological prophylaxis. The Journal of trauma, 66(5), 1436-1440.

9. Geerts, W. H., Code, K. I., Jay, R. M., Chen, E., \& Szalai, J. P. (1994). A prospective study of venous thromboembolism after major trauma. The New England journal of medicine, 331(24), 1601-1606

10. Brohi, K., Cohen, M. J., Ganter, M. T., Schultz, M. J., Levi, M., Mackersie, R. C., \& Pittet, J. F. (2008). Acute coagulopathy of trauma: hypoperfusion induces systemic anticoagulation and hyperfibrinolysis. The Journal of trauma, 64(5), 1211-1217

11. Sevitt, S., \& Gallagher, N. (1961). Venous thrombosis and pulmonary embolism. A clinicopathological study in injured and burned patients. The British journal of surgery, 48, 475-489.

12. Bendinelli, C., \& Balogh, Z. (2008). Postinjury thromboprophylaxis. Current opinion in critical care, 14(6), 673-678

13. Dunbar, N. M., \& Chandler, W. L. (2009). Thrombin generation in trauma patients. Transfusion, 49(12), $2652-2660$

14. Guan, W. J., Ni, Z. Y., Hu, Y., Liang, W. H., Ou, C. Q., He, J. X., ... \& Du, B. (2020). Clinical characteristics of coronavirus disease 2019 in China. New England journal of medicine, 382(18), 1708-1720.

15. Zhou, F., Yu, T., Du, R., Fan, G., Liu, Y., Liu, Z., ... \& Guan, L. (2020). Clinical course and risk factors for mortality of adult inpatients with COVID-19 in Wuhan, China: a retrospective cohort study. The lancet.

16. Wang, D., Hu, B., Hu, C., Zhu, F., Liu, X., Zhang, J., ... \& Zhao, Y. (2020). Clinical characteristics of 138 hospitalized patients with 2019 novel coronavirus-infected pneumonia in Wuhan, China. Jama, 323(11), 1061-1069 
17. Ruggieri, P., Trovarelli, G., Angelini, A. et al.COVID-19 strategy in organizing and planning orthopedic surgery in a major orthopedic referral center in an area of Italy severely affected by the pandemic: experience of the Department of Orthopedics, University of Padova. J Orthop Surg Res 15, 279 (2020).

18. Morelli, I., Luceri, F., Giorgino, R. et al.COVID-19: not a contraindication for surgery in patients with proximal femur fragility fractures. J Orthop Surg Res 15,285 (2020).

19. Demelo-Rodríguez, P., Cervilla-Muñoz, E., Ordieres-Ortega, L., Parra-Virto, A., Toledano-Macías, M., Toledo-Samaniego, N., García-García, A., García-Fernández-Bravo, I., Ji, Z., de-Miguel-Diez, J., ÁlvarezSala-Walther, L. A., Del-Toro-Cervera, J., \& Galeano-Valle, F. (2020). Incidence of asymptomatic deep vein thrombosis in patients with COVID-19 pneumonia and elevated D-dimer levels. Thrombosis research, 192, 23-26

20. Middeldorp, S., Coppens, M., van Haaps, T. F., Foppen, M., Vlaar, A. P., Müller, M., Bouman, C., Beenen, L., Kootte, R. S., Heijmans, J., Smits, L. P., Bonta, P. I., \& van Es, N. (2020). Incidence of venous thromboembolism in hospitalized patients with COVID-19. Journal of thrombosis and haemostasis : JTH, 10.1111/jth.14888

21. Kitagawa, K., \& Sakoda, S. (2009). Rinsho shinkeigaku = Clinical neurology, 49(11), 798-800

22. Ruiz, A. J., Hill, S. L., \& Berry, R. E. (1991). Heparin, deep venous thrombosis, and trauma patients. American journal of surgery, 162(2), 159-162

23. Hak D. J. (2001). Prevention of venous thromboembolism in trauma and long bone fractures. Current opinion in pulmonary medicine, 7(5), 338-343

24. Owings, J. T., Bagley, M., Gosselin, R., Romac, D., \& Disbrow, E. (1996). Effect of critical injury on plasma antithrombin activity: low antithrombin levels are associated with thromboembolic complications. Journal of Trauma and Acute Care Surgery, 41(3), 396-406

25. Seyfer, A. E., Seaber, A. V., Dombrose, F. A., \& Urbaniak, J. R. (1981). Coagulation changes in elective surgery and trauma. Annals of surgery, 193(2), 210-213

26. Enderson, B. L., Chen, J. P., Robinson, R., \& Maull, K. I. (1991). Fibrinolysis in multisystem trauma patients. The Journal of trauma, 31(9), 1240-1246

27. Attar, S., Boyd, D., Layne, E., McLaughlin, J., Mansberger, A. R., \& Cowley, R. A. (1969). Alterations in coagulation and fibrinolytic mechanisms in acute trauma. The Journal of trauma, 9(11), 939-965

28. Okamura, K., Nakagawa, I., Hidaka, S., Okada, Y., Kubo, T., \& Kato, T. (2008). Preoperative hypercoagulopathy in patients undergoing orthopedic lower extremity surgery. The Japanese journal of anesthesiology, 57(10), 1207-1212

29. Dries D. J. (1996). Activation of the clotting system and complement after trauma. New horizons (Baltimore, Md.), 4(2), 276-288

30. Engelman, D. T., Gabram, S. G., Allen, L., Ens, G. E., \& Jacobs, L. M. (1996). Hypercoagulability following multiple trauma. World journal of surgery, 20(1), 5-10

31. Meissner, M. H., Chandler, W. L., \& Elliott, J. S. (2003). Venous thromboembolism in trauma: a local manifestation of systemic hypercoagulability? The Journal of trauma, 54(2), 224-231 
32. Nicolaides, A. N., Kakkar, V. V., Field, E. S., \& Fish, P. (1972). Venous stasis and deep-vein thrombosis. The British journal of surgery, 59(9), 713-717

33. Myllynen, P., Kammonen, M., Rokkanen, P., Böstman, O., Lalla, M., Laasonen, E., \& Vahtera, E. (1987). The blood F VIII:Ag/F VIII:C ratio as an early indicator of deep venous thrombosis during posttraumatic immobilization. The Journal of trauma, 27(3), 287-290

34. Fujii, Y., Mammen, E. F., Farag, A., Muz, J., Salciccioli, G. G., \& Weingarden, S. T. (1992). Thrombosis in spinal cord injury. Thrombosis research, 68(4-5), 357-368

35. Bikdeli, B., Madhavan, M. V., Jimenez, D., Chuich, T., Dreyfus, I., Driggin, E., Nigoghossian, C., Ageno, W., Madjid, M., Guo, Y., Tang, L. V., Hu, Y., Giri, J., Cushman, M., Quéré, I., Dimakakos, E. P., Gibson, C. M., Lippi, G., Favaloro, E. J., Fareed, J., ... Lip, G. (2020). COVID-19 and Thrombotic or Thromboembolic Disease: Implications for Prevention, Antithrombotic Therapy, and Followup. Journal of the American College of Cardiology, S0735-1097(20)35008-7

36. Lodigiani, C., Iapichino, G., Carenzo, L., Cecconi, M., Ferrazzi, P., Sebastian, T., Kucher, N., Studt, J. D., Sacco, C., Alexia, B., Sandri, M. T., Barco, S., \& Humanitas COVID-19 Task Force (2020). Venous and arterial thromboembolic complications in COVID-19 patients admitted to an academic hospital in Milan, Italy. Thrombosis research, 191, 9-14

37. Wichmann, D., Sperhake, J. P., Lütgehetmann, M., Steurer, S., Edler, C., Heinemann, A., Heinrich, F., Mushumba, H., Kniep, I., Schröder, A. S., Burdelski, C., de Heer, G., Nierhaus, A., Frings, D., Pfefferle, S., Becker, H., Bredereke-Wiedling, H., de Weerth, A., Paschen, H. R., Sheikhzadeh-Eggers, S., ... Kluge, S. (2020). Autopsy Findings and Venous Thromboembolism in Patients With COVID-19. Annals of internal medicine, M20-2003

38. Cui, S., Chen, S., Li, X., Liu, S., \& Wang, F. (2020). Prevalence of venous thromboembolism in patients with severe novel coronavirus pneumonia. Journal of thrombosis and haemostasis : JTH, $10.1111 /$ jth. 14830

39. Klok, F. A., Kruip, M., van der Meer, N., Arbous, M. S., Gommers, D., Kant, K. M., Kaptein, F., van Paassen, J., Stals, M., Huisman, M. V., \& Endeman, H. (2020). Confirmation of the high cumulative incidence of thrombotic complications in critically ill ICU patients with COVID-19: An updated analysis. Thrombosis research, 191, 148-150

\section{Tables}

Table 1: Dermographic distribution of the patients 


\begin{tabular}{clc}
\hline & $n$ & mean \\
\hline Age (years) & & \\
Gender & 14 & \\
Male & 16 & \\
Female & 12 & \\
Farcture Side & 14 & \\
Right & $498-88)$ \\
Left & & \\
Bilateral & 12 & \\
Type of fracture & 5 & \\
Intertrochanteric femur fracture & \\
Femoral neck fracture & 4 & \\
Femur Diaphysis fracture & 2 & \\
Femur subtrochanteric fracture & 2 & \\
Femur distal fracture & 2 & \\
Tibial plateau fracture & 3 \\
Other fractures & $5,86(0,82-21,1)$ \\
D-dimer (mg/L) & $0,025(0,01-0,1)$ \\
Troponin (ng/mL) & Pozitive in 2 patient \\
\hline DVT finding on Doppler USG &
\end{tabular}

\section{Figures}




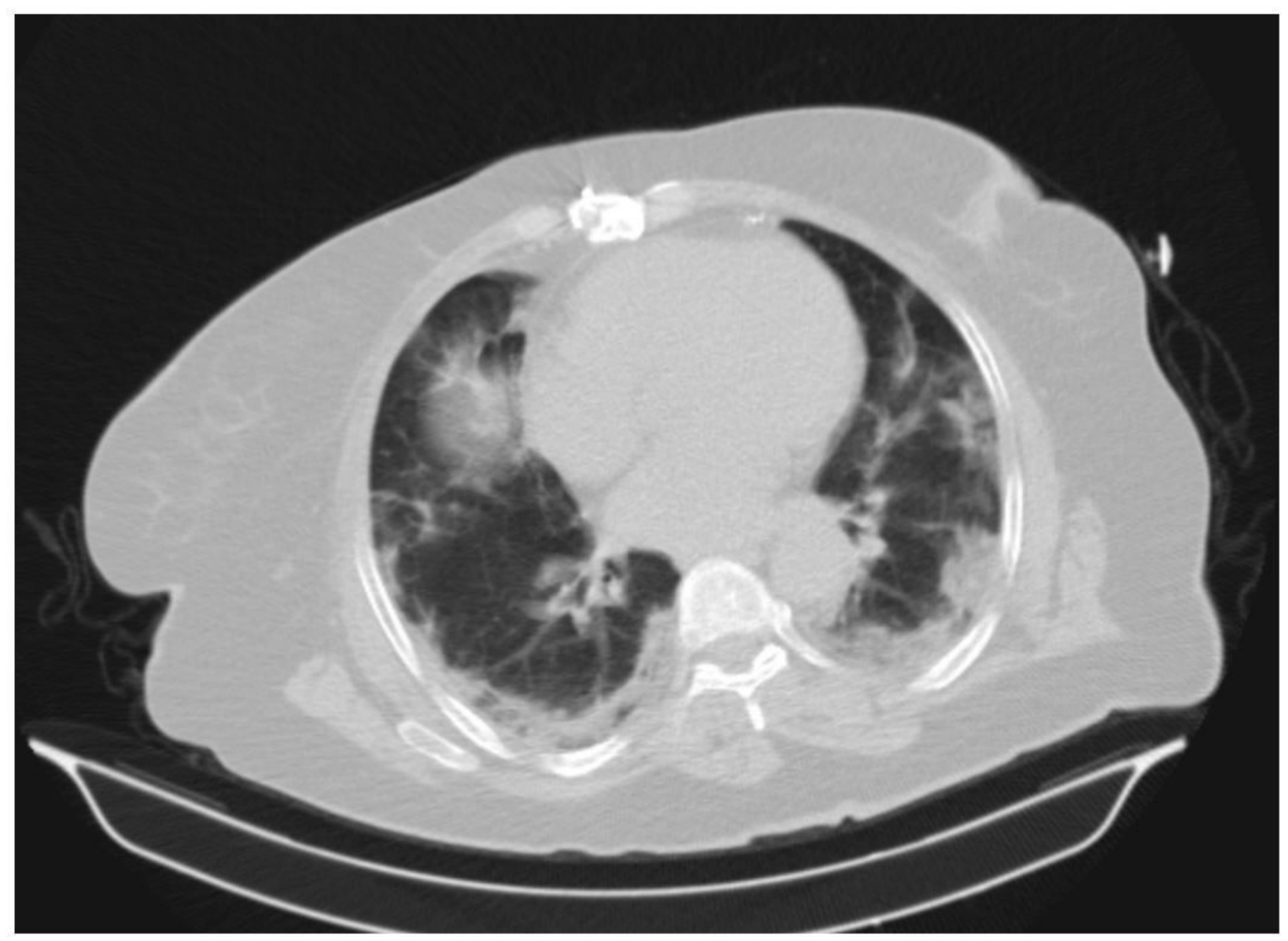

Figure 1

COVID-19 positive 58-year-old male patient hospitalized due to intertrochanteric fracture 


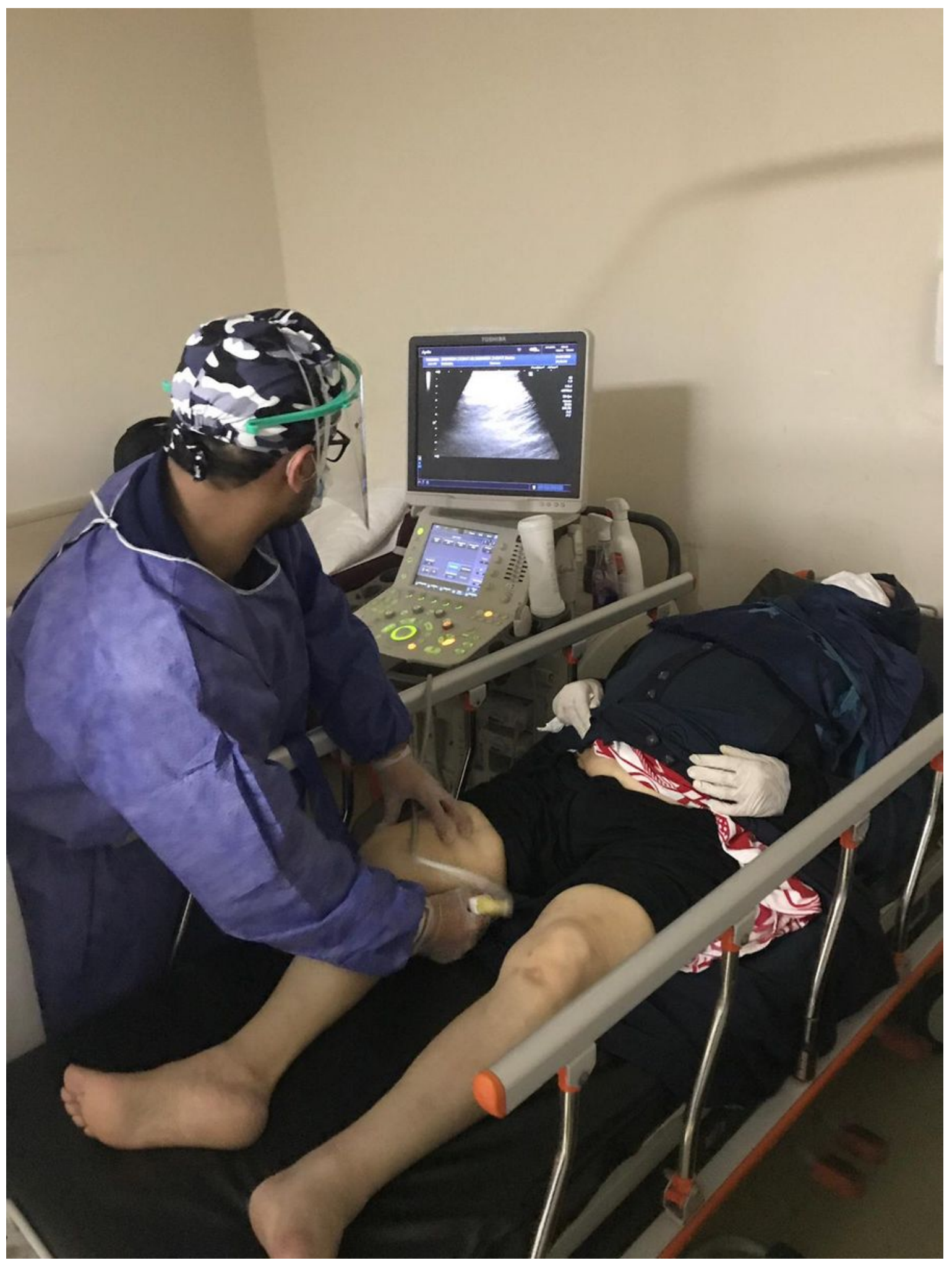

Figure 2

Doppler ultrasound application of COVID-19 positive patient 


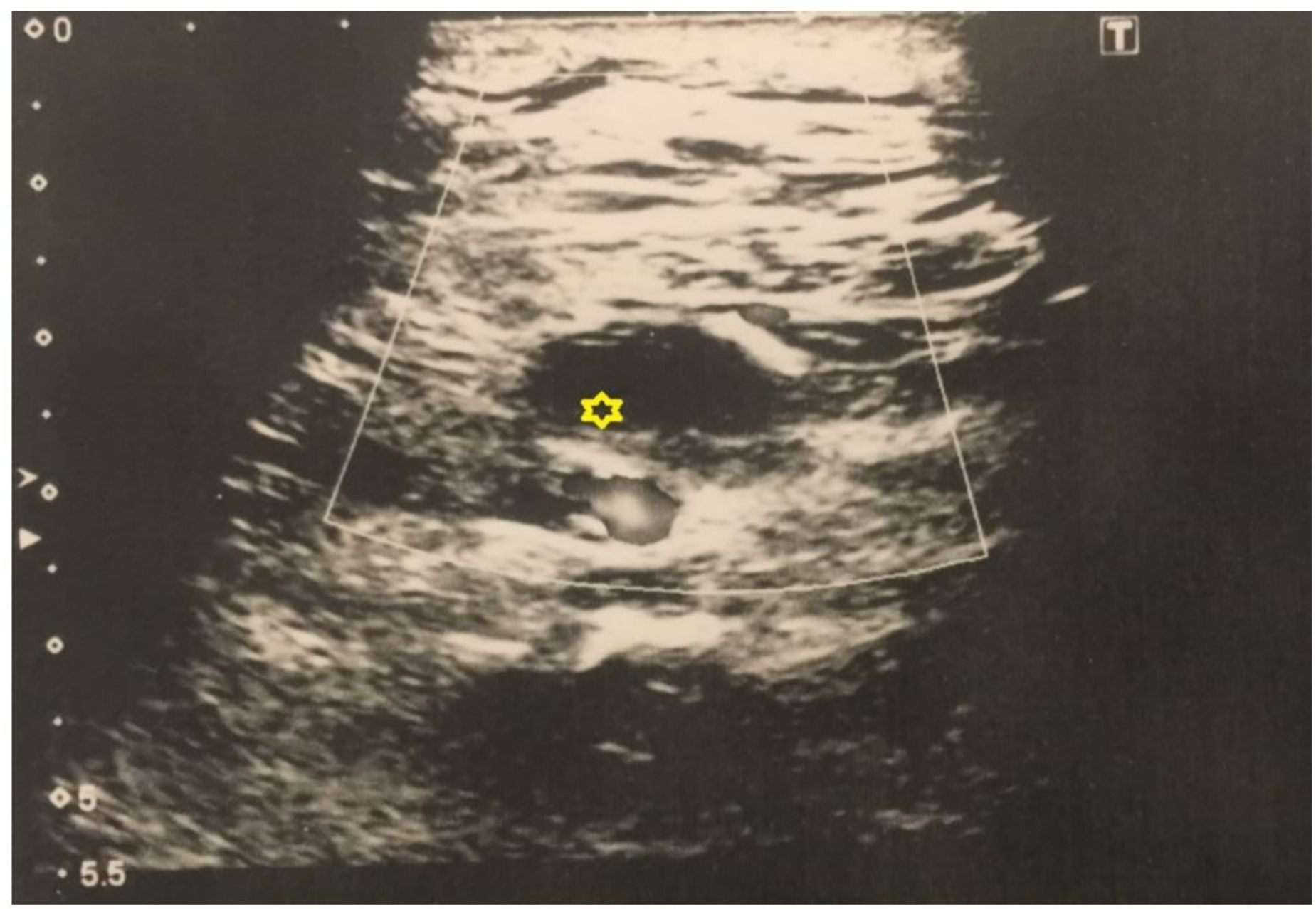

\section{Figure 3}

Doppler ultrasound image of a COVID-19 positive patient with a 79-year-old periprosthetic femur fracture ( $*$ thrombus formation in the popliteal vein) 


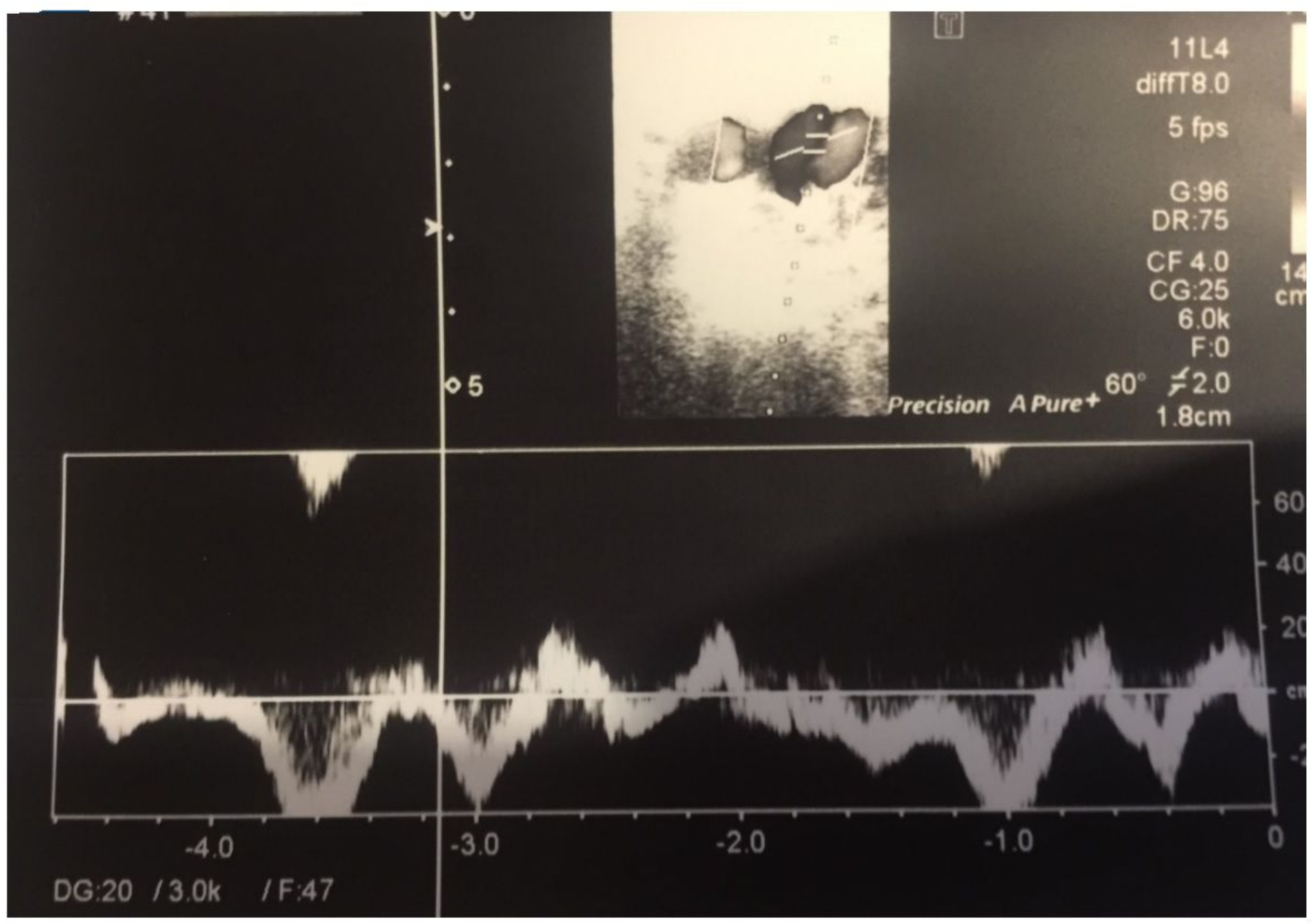

\section{Figure 4}

Doppler ultrasound image of a COVID-19 positive patient with a 70-year-old femoral neck fracture

\section{Supplementary Files}

This is a list of supplementary files associated with this preprint. Click to download.

- renameda8c35.pdf

- renamed3f9db.pdf

- renamed45649.pdf

- renamede3e76.pdf

- renamed75fdf.pdf

- renamedd9168.pdf 